\title{
HIV-associated dementia in the Dominican Republic: a consequence of stigma, domestic abuse and limited health literacy
}

\author{
Laura Frances Santoso, ${ }^{1}$ Emily E Erkkinen, ${ }^{1}$ Anindita Deb, ${ }^{1}$ Carlos Adon ${ }^{2}$
}

${ }^{1}$ University of Massachusetts Medical School, Worcester, Massachusetts, USA ${ }^{2}$ Instituto Dominicano de Estudios Virologicos, Santo Domingo, Dominican Republic

\section{Correspondence to} Laura Frances Santoso, laura.santoso@umassmed.edu

Accepted 5 April 2016

\section{CrossMark}

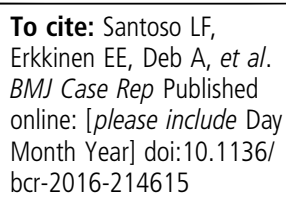

\section{SUMMARY}

A 38-year-old Dominican woman presented at an infectious disease clinic in Santo Domingo, with subacute dementia and psychomotor slowing. Based on physical findings and laboratory results, she was diagnosed with AIDS and HIV-associated dementia (HAD). She subsequently began combined antiretroviral therapy (CART). Psychiatric complications later emerged: the patient developed suicidal ideation and her partner expressed homicidal thoughts. After extensive interviewing, it was revealed that the patient had known her HIV-positive serostatus for years. However, several factors, including HIV stigma, mental illness stigma, domestic abuse and limited health literacy, had prevented her from seeking treatment and from disclosing her status to her partner. This patient's HIV was unmanaged as a consequence of social and educational circumstance, which resulted in severe sequelae, namely HAD. Compounded barriers to care can lead to the presentation of disease complications that are rarely seen today in countries with widespread access to antiretroviral therapy.

\section{CASE PRESENTATION \\ Initial presentation \\ Presentation and history}

A 38-year-old Dominican woman presented with a 1-month history of rapidly progressive cognitive decline and psychomotor slowing. Six days prior, she had sought treatment at a nearby hospital and tested positive for HIV. The patient recently lost her job because of her decreased productivity and now required assistance for basic activities of daily living (ADLs), including eating, bathing and walking. Despite her cognitive decline, she had insight into her condition, causing herself emotional distress. She reported decreased energy and appetite, joint pain and muscle pain. She denied any history of substance abuse.

\section{Physical examination}

On general examination, the patient had oral candidiasis and generalised lymphadenopathy. On neurological examination, the patient knew her name, but was disoriented to time and place. Her speech was bradyphrenic. She had slow extraocular pursuits, a flattened affect and decreased strength. She could walk alone but was cautious and required assistance. She had moderate-to-severe bradykinesia in walking, turning and initiating gait. Her gait had normal stance but decreased stride length and arm swing.

\section{Laboratory findings}

The patient's head CT demonstrated cortical atrophy in proportion to her age. Rapid HIV test was positive and her creatinine level was elevated at $1.7 \mathrm{mg} / \mathrm{dL}$. Viral load was 2668000 copies, CD4 count was $21 / \mu \mathrm{L}( \pm 30$ error) and $\mathrm{CD} 4 \%$ was $3 \%$ ( $\pm 3 \%$ error).

\section{Assessment and plan}

Available physical examination and laboratory findings were consistent with a diagnosis of AIDS and HIV-associated dementia (HAD). The differential diagnosis for change in cognition in the setting of HIV included toxoplasmosis, cryptococcosis, cytomegalovirus encephalitis, progressive multifocal leukoencephalopathy from John Cunningham virus, herpes encephalitis, lymphoma, and pseudodementia. Although no blood tests were available to exclude infection, the positive HIV test and normal CT scan prompted starting combined antiretroviral therapy (cART). After an adherence plan was developed, the patient was prescribed tenofovir/lamivudine and lopinavir/ritonavir.

\section{Follow-up}

Four weeks after the start of cART, the patient showed significant improvement. She was oriented to person, place and time, and engaged in complex conversation with intact comprehension and increased fluency. She stood, walked and turned with increased speed and no assistance. While unable to perform cognitive screens on initial presentation, she now scored a 3 of 30 on the Montreal Cognitive Assessment and a 3 of 12 on the International HIV Dementia Scale. Although these scores were far below the level of normal cognitive function, the patient's ability to participate demonstrated improvement. On the Lawton Instrumental Activities of Daily Living Scale, the patient completed 1 of 8 ADLs on her first day of presentation, which improved to a 6 of 8 on follow-up. The patient was unwilling to complete the Beck Depression Inventory-II.

Despite the patient's improvement, further interviewing revealed several issues impeding successful treatment. Her husband disclosed that he had been taking his spouse's prescribed HIV medications to self-treat. Additionally, the patient expressed guilt related to acquiring HIV and fear of further verbal abuse from her husband. She later cried and 
screamed suicidal wishes violently in the waiting room. In a private interview with the clinic's psychologist, her husband voiced homicidal thoughts in anger at the patient's diagnosis. When her physician attempted to refer the patient to a psychologist, she insisted that she was not 'crazy', but eventually agreed. The patient's neighbour disclosed to clinic staff that the patient had been aware of her HIV-positive serostatus for 14 years, but had neither sought care nor disclosed her status to her partner.

\section{GLOBAL HEALTH PROBLEM LIST}

- HIV stigma is still a significant barrier to healthcare access.

- Mental illness stigma is a barrier to healthcare access.

- HIV status disclosure places patients at risk for abuse from their partner.

- Limited health literacy in patients and patients' families reduces treatment adherence.

- HIV treatment is difficult to access for patients living in rural areas.

\section{GLOBAL HEALTH PROBLEM ANALYSIS}

HAD is the most severe manifestation of HIV-associated neurocognitive disorders (HAND). ${ }^{1}$ Although prevalence of HAD has significantly dropped since the advent of antiretroviral therapy (ART), it remains $10-25 \%{ }^{2}$ or higher where access to treatment is limited, particularly in the developing world.

At first, this case appeared to be an exceptionally rapid progression of HAD with just 1 month between initial symptoms and development of advanced dementia. However, extensive interviewing over several visits revealed that various social complexities obscured the true course of disease and now challenged successful treatment. This case demonstrates the extent to which HIV stigma, mental illness stigma, domestic violence, limited health literacy and limited access to treatment can impact patient care. As a consequence of these factors, this patient's HIV progressed to AIDS and led to serious neurological sequelae uncommon in countries with widely available ART.

\section{Strengths of the system}

The Dominican government has established several programmes, laws and campaigns, to limit the spread of HIV and support those already infected. These interventions helped HIV seroprevalence remain steady at $1 \%$ in 2002 and $0.8 \%$ in both 2007 and 2013. ${ }^{3}$ This case of AIDS and HAD occurred despite the existence of these supports.

All patients with HIV/AIDS can receive their ART free of charge by enrolling in the Dominican national programme. Our patient, who was seen at a private clinic, was able to receive three months worth of HIV medications for 300 Dominican pesos (around US\$7), a cost the clinic waives when patients say they cannot afford it. HIV testing is also routinely performed on pregnant women to prevent vertical transmission as a result of national advocacy, which is how we suspect this patient first learned of her status.

For over a decade, employment discrimination against people living with HIV/AIDS has been illegal. The HIV/AIDS law of 2012 guarantees basic rights for people with HIV. However, the law also controversially criminalises transmission of HIV and nondisclosure of HIV status. ${ }^{4}$ It is not clear how well these laws are enforced.

Extensive mass media interventions and lectures in schools and workplaces have also been launched by a government agency, CONAVIHSIDA (the National Council on HIV and AIDS), to educate safe sex practices and reduce HIV stigma.
Finally, the clinic where this patient ultimately received treatment is exemplary of high-quality care provided in a lowresource setting. The comprehensive services that were available at this clinic, which the patient had not sought elsewhere, augmented care and can be considered a strength of the system. This is discussed further in 'Future directions' section.

\section{Barriers to care}

Around the globe, stigma is a major challenge to HIV treatment. People living with HIV/AIDS in the Dominican Republic experience social devaluing as their illness is commonly associated with marginalised groups such as sex workers, the lesbian, gay, bisexual, and transgender (LGBT) community and drug users. Additionally, they are subjected to institutionalised discrimination, including denial of medical services or jobs. ${ }^{5}$ Fear of discrimination likely played a significant role in this patient's avoidance of treatment.

Limited public knowledge about mental health and the stigmatisation of psychiatric illnesses also present significant barriers to their treatment. The patient's husband thought that his wife's cognitive and motor decline was solely due to depression from her mother's death several months prior, and was thus unwilling to help the patient seek care. Although the husband's limited health literacy may have prevented him from suspecting another cause of cognitive decline, his disinterest in seeking medical attention demonstrates significant stigmatisation of mental illness. The husband's expanded description of the history also suggests that the patient's illness may have developed over a longer time course than originally described. Mental illness stigma also complicated the referral of our patient to a psychologist. Although the patient voiced suicidal intent, she was reluctant to see the psychologist for fear of being labelled as a 'loca' (crazy person). Locas are rejected in Dominican society for being perceived as being out-of-control, unpredictable and unable to fulfil expected gender roles. ${ }^{6}$

In the Dominican Republic, domestic violence is an epidemic that complicates HIV care. Countrywide, gender-based violence is the fourth leading cause of death of women of child-bearing age. ${ }^{7}$ HIV-positive women are often negatively perceived as sexually promiscuous, which can be considered an insult to their partners' 'machismo' (sense of manliness), and women who disclose their serostatus are at a greater risk of abandonment and abuse by their partners. ${ }^{8} 9$ Fear of domestic abuse may discourage women with HIV from seeking care. In this case, the patient's fear of abuse was validated when her partner accused her of promiscuity and expressed homicidal ideation after learning that she had HIV.

Medications are more susceptible to misuse in settings where patients have limited health literacy. Despite being educated about the patient's adherence plan, receiving instruction on how to set up a separate appointment for himself and being aware of the clinic's mission to treat all patients regardless of their financial situation, the patient's husband self-treated with his wife's medication.

Finally, limited availability of care did not seem to be the primary reason this patient did not access care, nevertheless, limited resources do impact patient treatment. It is common for clinicians to wait a full month to receive laboratory results. Our patient was diagnosed based on signs and symptoms and a rapid HIV test, without complete testing to exclude other differential diagnoses that would be routine in a high-resource setting. Additionally, there are only five HIV clinics in the Dominican Republic, although there are over 70 sites that dispense medications. The inconvenience of long travelling distances and wait 
times discourages patients from seeking treatment. Despite the severity of her symptoms, the patient did not arrive at our clinic until 6 days after she received a positive HIV test at a nearby hospital. This was in part due to her living several hours away by public transit and the need for her husband to miss work in order to bring her, which is a common scenario for many patients.

\section{Future directions}

The Dominican Republic and countries with similar barriers to care need to act at both, public health and individual clinic levels to improve the care of patients encountering problems described in this case. Although great strides have been made to reduce HIV seroprevalence, reinforcing policies and campaigns against discrimination in the Dominican Republic is necessary to address the stigma against HIV and mental illness that still runs deep in local culture. Other ongoing efforts to improve care include a plan to incorporate mental health services into standard primary care, ${ }^{10}$ which is a first step in addressing mental health illness. There is also a need for increased resources for victims of domestic violence, as current demand far exceeds the availability. Further widespread educational efforts would also be valuable to increase healthcare access and improve treatment compliance.

Various practices followed by the clinic where our patient received treatment may also be considered for use in other HIV treatment facilities. The Instituto Dominicano de Estudios Virológicos (IDEV, Dominican Institute of Virologic Studies), a clinic in Santo Domingo, the nation's capital, serves over 500 HIV patients a week with support from the government's national programme. This comprehensive care includes mental health services, education and outreach. Whereas there are only 3.17 psychologists for every 100000 population in the Dominican Republic, ${ }^{10}{ }^{11}$ IDEV employs two full-time psychologists to meet the mental health needs of HIV patients, who experience more neuropsychiatric complications than the

\section{Learning points}

- Stigma is sufficient to prevent care of treatable disease. Addressing HIV and mental illness stigma, and providing support, are critical to enable healthcare access.

- People living with HIVIAIDS are at a greater risk of abuse, and should be screened by health professionals for domestic violence.

- Patient and caretaker education is vital for successful treatment and should always accompany treatment interventions. general population. IDEV addresses their population's limited health literacy by employing an education director to give patients information about HIV, safer sex practices and counselling on medication adherence. IDEV also has an outreach programme aimed at detecting new HIV cases in high-risk populations and connecting people with continuous care. Twice weekly, a clinic team travels to rural and urban sites, administers rapid HIV tests and provides safe sex counselling.

This case demonstrates the extent to which social and cultural factors contribute to illness and hinder successful healthcare, even when treatment is available. Further interventions on governmental, communal and individual levels are needed to develop a system where people with HIV or mental illness can access care and sustain treatment without social costs.

Acknowledgements The authors extend their thanks to Dr Ellen Koenig and the staff at el Instituto Dominicano de Estudios Virologicos for their help in compiling and interpreting this case study.

Contributors LFS interviewed the patient, collected case data, analysed the case, and drafted and revised the manuscript. EEE interviewed the patient, collected case data, analysed the case, and drafted and revised the manuscript. $A D$ analysed the case and revised the manuscript. CA was the primary provider of the patient, collected case data, analysed the case and revised the manuscript.

Competing interests None declared.

Patient consent Obtained.

Provenance and peer review Not commissioned; externally peer reviewed.

\section{REFERENCES}

1 Antinori A, Arendt G, Becker JT, et al. Updated research nosology for HIV-associated neurocognitive disorders. Neurology 2007;69:1789-99.

2 Rosca EC, Rosca O, Simu M, et al. HIV-associated neurocognitive disorders: a historical review. Neurologist 2012;18:64-7.

3 PEPFAR. The United States Emergency Plan for AIDS Relief. Dominican Republic 2014 Country Operational Plan Executive Summary. 2015 (cited 8 November 2015). http://www.pepfar.gov/documents/organization/240256.pdf

4 Ley No. 135-11, DN [statute on the internet]. 2011 (cited 8 November 2015). http://www.poderjudicial.gob.do

5 Rojas P, Malow R, Ruffin B, et al. The HIV/AIDS epidemic in the Dominican Republic: key contributing factors. I Int Assoc Physicians AIDS Care 2011;10:306-15.

6 Collins PY, von Unger H, Armbrister A. Church ladies, good girls, and locas: stigma and the intersection of gender, ethnicity, mental illness, and sexuality in relation to HIV risk. Soc Sci Med 2008;67:389-97.

7 The Government of the Dominican Republic and UNFPA. Plan de Acción del Programa de País 2012-2016. 2011 (cited December 2015). http://countryoffice. unfpa.org/dominicanrepublic/drive/CPAP2012-2016UNFPARD(Oficial).pdf

8 Beaulaurier RL, Craig SL, De La Rosa M. Older Latina Women and HIV/AIDS: an examination of sexuality and culture as they relate to risk and protective factors. J Gerontol Soc Work 2009;52:48-63.

9 Henry J. Kaiser Family Foundation. Stigma, gender violence placing women in Caribbean at increased risk of HIV. 2009 (cited 8 November 2015). http://www. thebody.com/content/art51676.html

10 WHO. WHO Mental Health Atlas-2011 Country Profiles. 2011 (cited December 2015). http://www.who.int/mental_health/evidence/atlas/profiles/dom_mh_profile. pdf?ua $=1$

11 WHO. WHO-AIMS Report on Mental Health Systems in Central American and the Dominican Republic. 2009 (cited December 2015). http://www.who.int/mental_ health/evidence/report_on_mental_health_systems_2009_ENG.pdf 


\section{Global health}

Copyright 2016 BMJ Publishing Group. All rights reserved. For permission to reuse any of this content visit http://group.bmj.com/group/rights-licensing/permissions.

BMJ Case Report Fellows may re-use this article for personal use and teaching without any further permission.

Become a Fellow of BMJ Case Reports today and you can:

- Submit as many cases as you like

- Enjoy fast sympathetic peer review and rapid publication of accepted articles

- Access all the published articles

- Re-use any of the published material for personal use and teaching without further permission

For information on Institutional Fellowships contact consortiasales@bmjgroup.com

Visit casereports.bmj.com for more articles like this and to become a Fellow 